2 Research Square

Preprints are preliminary reports that have not undergone peer review.

They should not be considered conclusive, used to inform clinical practice,

or referenced by the media as validated information.

\title{
Sustainable Thermochemical Extraction of Amorphous Silica From Biowaste
}

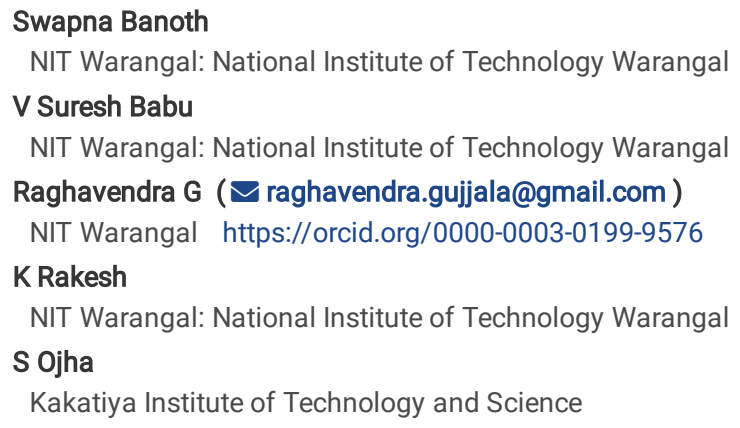

NIT Warangal: National Institute of Technology Warangal

V Suresh Babu

NIT Warangal: National Institute of Technology Warangal

Raghavendra G ( raghavendra.gujjala@gmail.com )

NIT Warangal https://orcid.org/0000-0003-0199-9576

K Rakesh

NIT Warangal: National Institute of Technology Warangal

S Ojha

Kakatiya Institute of Technology and Science

\section{Research Article}

Keywords: Agricultural waste, Rice hull ash (RHA), acid leaching, photoluminescent, XRD, SEM \& EDS.

Posted Date: July 1st, 2021

DOI: https://doi.org/10.21203/rs.3.rs-657645/v1

License: (c) (i) This work is licensed under a Creative Commons Attribution 4.0 International License. Read Full License

Version of Record: A version of this preprint was published at Silicon on August 16th, 2021. See the published version at https://doi.org/10.1007/s12633-02101293-z. 


\section{Abstract}

The objective is to utilize zero wastage rice hull material which contains major component silica in amorphous and used as reinforcement material for various applications. Burning of hull in controlled condition after removal of metal ions leads to white silica of high purity. An economical method for extraction of amorphous natural silica by thermochemical treatment (pyrolysis process) is performed. The pyrolyzed biomass at four different temperatures is observed for treated and untreated rice hull. Calcination of rice hull at $600^{\circ} \mathrm{C}$ in muffle furnace turns into white amorphous natural silica. In this research, inorganic acid $\mathrm{HCl}$ is used to retrieve silica from rice hull. Synthesized Silica is characterized by $\mathrm{X}$-ray diffraction analysis, which indicates that the silica is amorphous form, it displayed a strong broad peak at $22.32^{\circ}$ and $21.52^{\circ}(2 \mathrm{q})$. The FT-IR data was revealed the existence of peaks at $4000 \mathrm{~cm}^{-1} \& 400 \mathrm{~cm}^{-1}$ showing the siloxane \& silanol groups were present, Fluorescence Spectrophotometer, SEM and EDS.

\section{Introduction:}

Rice hull is the waste biomass and good source for the production of silica about 50\%-90\%, majorly cultivated crop in the world [1-2]. Verities of sources are available for the synthesized amorphous silica, among them one of the simple and good sources is rice hull, which has a large amount of silica up to $22 \%$. Rice hull on a weight basis accounts for an average of $20 \%$ by-product from the milling process, of the paddy crop [3-4]. $\mathrm{RH}$ is the agricultural waste available abundantly in more volume and acts as a source for the production of amorphous silica, mass production of RH can be used economically at a low-cost source of amorphous silica [5]. Combustion of RH under the constrained conditions leads to produce RHA, which possesses almost pure silica. The metal impurities, i.e. $\mathrm{Fe}, \mathrm{Mn}, \mathrm{Na}, \mathrm{Ca}, \mathrm{K}$ and $\mathrm{Mg}$, which effect the color and purification of the $\mathrm{SiO}_{2}$ are removed by the pre-treatments with inorganic acids like $\mathrm{HCl}$, $\mathrm{H}_{2} \mathrm{SO}_{4}$ or $\mathrm{HNO}_{3}$ before combustion [6]. Two forms of $\mathrm{SiO}_{2}$ occur in nature Amorphous and crystalline. Opal is the amorphous form of silica and crystalline occurs in three forms namely cristobolite, quartz and tridymite. Normally silica in RH being of bioquenic is essential of amorphous nature. At different temperatures and heat treatment crystalline form of silica is obtained [7].

The importance of the amorphous form of silica contained in its form, when it compared with a crystalline form of silica because of inactiveness and inability to involve in the chemical reactions [8]. Also, by latest survey and study gives clear information that RH is a large content of natural amorphous silica [9]. Applications of silicates acquired from $\mathrm{SiO}_{2}$ were used in the ceramics industry, and in cement production majorly, in biomedical, cosmetics, detergents as filler material [10]. Silica was employed as the main primary substance for the production of many inorganic materials and metal-based complexes, organic

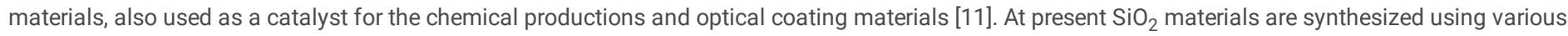
methods, such as sodium silicate, sol-gel route, template synthesis, emulsions-based synthesis, and bio-inspired methods [12]. Leaching by acids [13] and gasification [14] process have been used for recovering $\mathrm{SiO}_{2}$ from $\mathrm{RH}$. By extraction of alkali at low temperatures, amorphous $\mathrm{SiO} 2$ from $\mathrm{RHA}$ can be extracted, amorphous silica solubility is less at $\mathrm{pH}<10$ and penetratingly raise $\mathrm{pH}>10$. This unique behavior concerning solubility can extract $\mathrm{SiO} 2$ in the purest form under alkaline conditions and simultaneously precipitating at a low PH value [15]. Metallic sulphate formations which are insoluble in water were normally used with organic acid (H2SO4) during the acid pretreatment stage of the RH. Also, HNO3 is not efficient and cheaper than $\mathrm{HCl}$. Due to the eutectic reaction, some of the metal impurities were removed when melting temperature of silica from RHA. The inorganic compounds contained within the RH reached about $20 \%$ wt of the dry hull with silica occupying $94 \%$ wt of the total while (K2O), ( $\mathrm{CaO})$, (MgO), (Al2O3), and (P2O5) constituting the remaining $6 \%$ in descending order of concentrations [16].

In this paper, the effect of inorganic hydrochloric acid is used for the removal of organics and metallic impurities from $\mathrm{RH}$ during the acid pre-treatment stage. The properties studied include functional groups determination by FTIR spectroscopy and the percentage purity of the generated silica particles would be ascertained by XRD, fluorescence spectrometer, surface morphology by SEM and wt\% by EDS analysis.

\section{Materials And Methods}

\subsection{Acid washing}

Inorganic acid washing was used to remove small amounts of impurities and minerals before extracting silica from RHA in the following method. Initially, $1 \mathrm{M}$ $\mathrm{HCl}$ solution is prepared (i.e, $8.36 \mathrm{ml}$ of conc. $\mathrm{HCl}$ is added to $91.64 \mathrm{ml}$ of tap water), Now 20 grams of RHA samples were immersed in $100 \mathrm{ml}$ solution. This solution is leached for $2 \mathrm{hrs}$ on a hot pan at $80^{\circ} \mathrm{C}$ and water washed then filtered by filter paper to remove impurities.

RHA deposits are finally washed with $100 \mathrm{ml}$ of tap water as shown in Fig. 1. The residues were utilized for the extraction of silica. Draining off acid from the $\mathrm{RH}$ and again rinsed with tap water until the free from acids or up to convert to neutral $\mathrm{pH}$, the filtered by filter paper then air-dried. The acid-treated $\mathrm{RH}$ has dried over sunlight up to $48 \mathrm{~h}$. The un-treated $\mathrm{RH}$ and acid-treated $\mathrm{RH}$ were placed in the muffle furnace at $550,600,650$, and $700{ }^{\circ} \mathrm{C}$ for $3 \mathrm{~h}$ then resulting in an un-leached RHA and acid-leached RHA respectively. Treating the rice hull at boiling temperatures with acid solution [6] was done and extended [4] so that a large amount of impurities eliminates otherwise glassy phase formation takes place. Pre-treatment of the RHs and $\mathrm{RHAs}$ with $\mathrm{HCl}$ after the calcination process was having a capacity for the impurities removal and results in the production of a white RHA. SiO2 levels were found to be higher than some values reported in the literature. The values found by, [17], [18] and [19] were $78.44,91.40,94.95$, and $84.10 \%$ of Silica respectively.

\subsection{Extraction of Silica}

Collection of rice hull from nearby Rice mill soaked for $1 \mathrm{hr}$ in salt water and made dried till the moisture is removed. Dried $\mathrm{RH}$ is treated with $1 \mathrm{M}$ Conc. $\mathrm{HCl}$ same procedure adopted with small modifications. The leaching operation is carried out for $2 \mathrm{hrs}$ along with continuous stirring till the temperature attains $80^{\circ} \mathrm{C}$. The acid solution is removed from the boiled rice hull employing water wash, then again dried for $24 \mathrm{hrs}$. The dried acid-treated $\mathrm{RH}$ is kept in the muffle furnace for $3 \mathrm{hrs}$ at $550,600,650$ and $700^{\circ} \mathrm{C}$ and cooled overnight and the powder which is extracted is the white natural amorphous silica. 


\subsection{Characterization Study}

X-Ray diffraction was experimented by using PAN analytical X'Pert PRO by a Cu Ka radiation. The silica powder is placed on Bragg-Brentano optics on a flat plate. Divergence slit was fixed in order to limit the beam flow on the sample at angles of $2 \theta$. X-ray Diffraction (XRD) sample type is powder form used for crystallography analysis and identification of phases. The parameters taken were scatter angle of $5^{\circ}$ to $90^{\circ}$ for time $13 \mathrm{~min}$ with step size of $0.016^{\circ}$. Fourier transform infrared spectroscopy (FTIR, Bruker,USA) is the additional characterization was done the silica powder is mixed with $\mathrm{KBr}$ window material in the ratio of 1:100 and blended to obtain smooth surface for testing, then compacted in hydraulic press in order to form pellets transmittance measurements.

SEM analysis was conducted by using VEGA3 TESCAN of powdered sample was performed at $15.0 \mathrm{kV}$ accelerating voltage under higher vacuum and at a magnification of $7.00 \mathrm{kx}$. The Agilent cary eclipse fluorescence spectrometer is used for fluorescent measurements with high sensitivity. A solid sample device used to hold many sample types powders, gels, fabrics optical components. Measures minute sample quantities deposited on the sides.

\section{Results And Discussions}

The microstructural, compositional analysis and morphological of RHA-Silica was executed throughout material characterization techniques such as an XRD, FTIR, Fluorescence Spectrometer, SEM and EDS.

The X-Ray diffraction (XRD) model was achieved and functioned at $45 \mathrm{kV} \& 30 \mathrm{~mA}$ and $2 \theta$ in the range between $5^{\circ}$ to $50^{\circ}$. The structural pattern of the sample was analyzed and recorded in the Software. XRD patterns of the untreated silica and $\mathrm{HCl}$ treated silica at the different combustion temperatures are represented in figure-2A and $2 B$, respectively. The broad diffused peak was observed with maximum intensity at $2 \theta=22^{\circ}$, this sharp peak was indicates silica was amorphous.

However, increase the sharpness of this peak with increases of the combustion temperatures and observed the less amorphous/less crystallization nature at lower temperatures $550{ }^{\circ} \mathrm{C}$ for untreated silica as presented in Figure-2A. It gives clear information about silica, if increase the temperature, the crystallization nature was increased it indicates that the crystallization transformation of silica does not occur at $700{ }^{\circ} \mathrm{C}$.

Meanwhile, synthesized silica was shown completely amorphous nature at below $700^{\circ} \mathrm{C}$, based on the different temperatures, this synthesized silica shows a clear sharp peak with the appearance of amorphous nature at $600{ }^{\circ} \mathrm{C}$. This is due to the alkali metals removal while leaching and also of eutectic reaction with $\mathrm{SiO}_{2}$. Silica XRD spectra were shown in Fig. $2 \mathrm{~A}$, broad strong peak at $22.32^{\circ}$ and $21.52^{\circ}$ is observed for both treated and untreated $\mathrm{SiO}_{2}$ which reveals the amorphous nature of silica. The empirical broad halo $\left(\mathrm{SiO}_{2-} \mathrm{T} 2\right)$ with maximum intensity at $2 \theta=22^{\circ}$ was confirmed the amorphous structure of obtained silica similar results are shown [20] extracted $\mathrm{SiO}_{2}$ nanoparticles from $\mathrm{RH}$ and resulted in a broad peak at an angle of $22^{\circ}$ [21].

And investigated sharp peaks absence in the (scanning angles) range reports that no crystalline structures are noticed.

The sample is prepared in the form of KBr pellets and the range is detected from $4000 \mathrm{~cm}^{-1}$ and $400 \mathrm{~cm}^{-1}$. The FTIR spectrum of the untreated amorphous silica \& acid-treated amorphous silica at $600^{\circ} \mathrm{C}$ is displayed in Figure-3 (combustion at $600{ }^{\circ} \mathrm{C}$ was taken as an example \& the spectra of the amorphous silica at another combustion temperatures were exhibiting similar to that which are amorphous). The strong absorption peaks were displayed at $810 \mathrm{~cm}^{-1}$ and 452 $\mathrm{cm}^{-1}$. These absorption band peaks revealed that the formation of the Si-O-Si bond, which's an important aspect of the amorphous silica. The peak shown at $1096 \mathrm{~cm}^{-1}$ was tells about the formation of $\mathrm{Si}-0-\mathrm{Si}$ asymmetric stretching vibration in the fingerprint region [22]. The starching vibration of the functional group $\mathrm{O}-\mathrm{H}$ broadband with a broad band is shown at $3800-3000 \mathrm{~cm}^{-1}$ region with various forms of hydroxyl groups, i.e. silanol hydroxyl groups (O-H). Based on previous reports [23] also designate that $-\mathrm{OH}$ peak expansion can occur due to physically and chemically adsorbed water molecules.

Some what a sharp peak observed at $3750-3740 \mathrm{~cm}^{-1}$ region is furnish to the stretching frequency of the hydroxyl group ( 0 - $\mathrm{H}$ ) and the peak was displayed around at $1633 \mathrm{~cm}^{-1}$ is recognized to the bending vibrations of the $\mathrm{O}-\mathrm{H}$ bonds in adsorbed water molecule on the outside of amorphous silica. Synthesized from of RHA was designate that they are in the amorphous form of silica [24]. The FTIR spectrographs and analysis for the treated and untreated silica were described in Figure-3A \& 3B respectively.

The structure of silica is shown in Fig. 4. synthesized natural silica was characterized by UV-Visible (absorption) and photoluminescent (emission) spectra were studied in $1 \mathrm{mM}$ solubilized in $\mathrm{CHCl}_{3}$ at room temperature. Towards this, the wavelength of UV-Visible absorption (wavelength range is $350 \mathrm{~nm}$ to 450 $\mathrm{nm}$ ) band maxima was demonstrated at $367 \mathrm{~nm}$ (as represented in figure-5 (A)), which shows impressive absorption band coincided with amorphous nanosilica [25] which was comparable with previous reports [26].

And the corresponding photoluminescent (emission) spectra displayed a short peak at $453 \mathrm{~nm}$ and a sharp intensity peak at $488 \mathrm{~nm}$ as shown in fig-5-(B) it is comparable with amorphous nano-silica [27] and with comparison to $\mathrm{nm}$ for the sterilized $\mathrm{SiO}_{2}$ nanoparticles [28], Its strong PL emission has enhanced the photostability [29]. These photophysical data was showing changes with other sterilized $\mathrm{SiO}_{2}$ nanoparticles and amorphous silica nanoparticles [30]. This natural silica emission spectra were exhibiting co-relation with $\mathrm{SiO}_{2}$ nanoparticles.

Outer surface morphology is shown in Fig. 6. of acid-treated rice hull. The morphology of the rice hull is irregular and not smooth. The outer surface appearance has rugged patterns that indicate the presence of silica. No silica or less silica has appeared at the inner surface of rice hull fiber. After completion of the acid treatment, significant changes were observed in rice hull morphology.

The surface of untreated rice hull reveals higher roughness than treated with acids because of hydrolysis with some of the organic components by the acid. SEM analysis showed agglomerated ORHA, which may be due to the presence of hydrogen bonding between Silanol groups on the surface of rice husk ash 
for FRHA[31].

This confirmed the high percentage purity of amorphous silica particles that were synthesized shows other element's traces were absent by the peaks indicated in Fig. 7. Oxygen and Silicon presence were revealed by the formation of Si-OH groups (silanol) and Si-O-Si bonds (siloxane). bonds were together made silicon \& oxygen to be present. The amorphous silica particles were composed of $45.56 \% \mathrm{Si}$ and $54.44 \% \mathrm{O}$ noticed by EDS to the stoichiometric composition of $\mathrm{SiO}_{2}$. The comparison is shown in table 1 .

Table.1: Chemical Compositions of SiO2 for Commercial type and synthesized type

\begin{tabular}{|llll|}
\hline Type of Silica & Silica (wt \%) & O (wt \%) & C (wt \%) \\
\hline Commercial Silica & 47.68 & 44.64 & 7.68 \\
Synthesized Silica & 45.56 & $54.44 \%$ & - \\
\hline
\end{tabular}

\section{Conclusion}

The quality of the silica from the rice hull leads to a problem, it certainly agglomerates. By a specific sample preparation method, size reduction could be accomplished, and an amorphous silica sample that was acquired by the burning of rice hull at $600{ }^{\circ} \mathrm{C}$, after leaching of the raw material with $1 \mathrm{M} \mathrm{HCl}$, existing a homogeneous particle size distribution. The X-ray diffractograms exhibit a strong broad peak at $22.14^{\circ}$. It reveals that synthesized silica from RHA was amorphous. However, the XRD results showed the presence of silica and its derivative suggests that materials fabricated from this biomass will certainly possess good results when a strength point of view was considered. Absorption ( $367 \mathrm{~nm})$ \& fluorescent (488 nm) spectra showing their impressive sharp peaks which indicated its natural silica presence and FTIR data showed the occurrence of the hydrogen-bonded siloxane group (Si-O-Si) and silanol (Si-OH) groups in amorphous silica. Amorphous silica chemical compositions revealed by EDS were near to commercially available silica. The rice hull ash (RHA) has various applications in marketing sectors all over the sphere. Like water glass production, it increases hydrophobic property in the case of concrete and cement, acts as an additive in the rubber industry also used in the fabrication of ceramics.

\section{Declarations}

\section{Ethics approval and Consent to participate: not applicable}

\section{Consent for publication: Yes}

Availability of data and material: The experimental data are available and all the information is provided in the paper.

\section{Competing interests: No}

Funding: No funding

Author contributions: Prof. Suresh babu, professor in the Mechanical Engineering Department, NIT, Warangal have framed the design and development of the project.

Dr. Raghavendra is one of the principle investigator of the project and also corresponding author for the current research paper, alongside proof reading and important insights were provided in revising the article with most appropriate suggestions.

Swapna, Research scholar at Mechanical Engineering Department, NIT, Warangal have worked on processing of the fabrication and conducted all the studies and drafting the research article.

Rakesh K, Research scholar in the Department of mechanical, National Institute of Technology, Warangal material characterization for microstructural studies which helped us in completing the part of a project on time.

Shakuntala ojha, Assistant professor Department of mechanical engineering, KITS Warangal, India helped in the characterization.

\section{Acknowledgments}

The authors would like to thank the chairman and Principal of KITS and Director of NIT-Warangal, faculty members and laboratory staff of Mechanical Engineering Departments for their support to completion of this work.

\section{Compliance with ethical standards:}

the research work is original work all the standards are taken in consideration

Conflict of interest: No conflict of interest

Research involving Human Participants and/or Animals: no animals or human studies are involved.

Informed consent: not applicable 


\section{References}

[1] A. Bazargan, M. Bazargan, G. McKay (2015), Optimization of rice husk pretreatment for energy production Renew. Energy, 77 pp. 512520.

https://doi.org/10.1016/j.renene.2014.11.072

[2] L.W.O. Soares, R.M. Braga, J.C.O. Freitas, R.A. Ventura, D.S.S. Pereira, (2015),

The effect of rice husk ash as pozzolan in addition to cement Portland class G for oil well cementing J. Petrol. Sci. Eng., 131 pp. $80-85$.

https://doi.org/10.1016/j.petrol.2015.04.009

[3] D. An, Y. Guo, Y. Zhu, Z. Wang (2010)A green route to preparation of silica powders with ricehusk ash and waste gas Chem. Eng. J., 162 , pp. 509-514, https://doi.org/10.1016/j.cej.2010.05.052

[4] E.P. Ng, H. Awala, K.H. Tan, F. Adam, R. Retoux, S. Mintova (2015) EMT-type zeolite nanocrystals synthesized from rice husk Microporous Mesoporous Mater., pp. 204-209, https://doi.org/10.1016/j.micromeso.2014.11.017

[5] Dominic M et al (2020) Green tire technology: effect of rice husk derived nanocellulose (RHNC) in replacing carbon black (CB) in natural rubber (NR) compounding. Carbohydr Polym 230:115620. https://doi.org/10.1016/j.carbpol.2019.115620

[6] Yalcin N and Sevinc V. (2001) Studies on silica obtained from rice husk. Ceramics International. 27: 219-24 https://doi.org/10.1016/S0272-8842(00)000687

[7] Bajirao S. Todkar , Onkar A. Deorukhkar (2016) Extraction of Silica from Rice Husk International Journal of Engineering Research and Development e-ISSN: 2278-067X, p-ISSN: 2278-800X

[8] Al Soubaihi RM et al (2020) Synthesis of hierarchically porous silica aerogel supported palladium catalyst for low-temperature CO oxidation under ignition/extinction conditions. Microporous Mesoporous Mater 292:109758. https://doi.org/10.1016/j.micromeso.2019.109758

[9] Chun J et al (2020) Synthesis of ordered mesoporous silica with various pore structures using high-purity silica extracted from rice husk. J Ind Eng Chem 81:135-143. https://doi.org/10.1016/j.jiec.2019.08.064

[10] Anon., 1997. Soluble Silicates and their Applications. Crossfield Publication, Crossfield, Warrington, UK, Issue No. 2.

[11] Le NH et al (2020) Photo-induced generation of size controlled au nanoparticles on

pure siliceous ordered mesoporous silica for catalytic applications. Microporous Mesoporous Mater 295:109952. https://doi.org/10.1016/j.micromeso.2019.1(

[12] Liou T.H. and Wu S.J., (2010). Kinetics study and characteristics of silica nanoparticles produced from biomass-based material. Industrial and Engineering Chemistry Research 49: https://doi.org/10.1021/ie100050t

[13] Chakraverty, A., Kaleemullah, S., (1991). Conversion of rice husk into amorphous silica and combustible gas. Energy Consers. Mgmt. 32, 565 \pm 570 . https://doi.org/10.1016/0196-8904(91)90116-Z

[14] Luan, T.C., Chou, T.C., (1990). Recovery of silica from the gasi®cation of rice husk/coal in the presence of a pilot 'ame in a modi®ed ' ${ }^{-}$uidized bed. Ind. Eng. Chem. Res. 29, 1922 1927 https://doi.org/10.1021/ie00105a026

[15] Acid Leaching as Efficient Chemical Treatment For Rice Husk in Production of Amorphous Silica Nanoparticles Abdullahi Mahmud et.al ARPN Journal of Engineering and Applied Sciences ISSN 1819-6608.

[16] Amick, J.K. J. Purification of Rice Hulls as a Source of Solar Grade Silicon for Solar Cells Electrochem. Soc., v. 129, p. 864-866, 1982. https://doi.org/10.1149/1.2123989

[17] M.K.D. Rambo, A.L. Cardoso, D.B. Bevilaqua, T.M. Rizzetti, L.A. Ramos, G.H. Korndö rfer, A.F. Martins (2011) Silica from rice Husk Ash as an additive for rice plant J. Agron., 10, pp. 99-104, 10.3923/ja.2011.99.104

[18] V. Della, I. Kuhn, D. Hotza 9 (2002) Rice husk ash as an elemente source for active silica production Mater. Lett., 57 , pp. $818-$

821, https://doi.org/10.1016/S0167-577X(02)00879-0

[19] R.P. Chauhan, A. Kumar Radon (2013), resistant potential of concrete manufactured using Ordinary Portland Cement blended with rice husk ash Atmos.Environ., 81 pp. 413- 420.https://doi.org/10.1016/j.atmosenv.2013.09.024

[20] U. Kalapathy, A. Proctor, J. Shultz (2002), An improved method for production of silica from rice hull ash Bioresour. Technol., 85 pp. 285289. https://doi.org/10.1016/S0960-8524(02)00116-5

[21] Ma X, Zhou B, Gao W, Qu Y, Wang L, Wang Z, Zhu Y (2012) A recyclable method for production of pure silica from rice hull ash. Powder Technol 217:497501. https://doi.org/10.1016/j.powtec.2011.11.009 
[22] Yalc N, Sevinc V (2001) Studies on silica obtained from rice husk. Ceram Int 27:219- 224. https://doi.org/10.1016/S0272-8842(00)00068-7

[23] Y. Liu, Y. Guo, Y. Zhu, D. An, W. Gao, Z. Wang, Y. Ma, Z. Wang, J. Hazard. Mater. 186 (2011) 1314-1319. https://doi.org/10.1016/j.jhazmat.2010.12.007

[24] Guo Y., Wang M., Zhang H., Liu G., Zhang L. and Qu X., (2008). The surface modification of nanosilica, preparation of nanosilica/acrylic core-shell latex, and is application in toughening PVC matrix. Journal of Applied Polymer Science 107: 2671-2680. https://doi.org/10.1002/app.27310

[25] W.A.P.J. Premaratne, (2013) synthesis Of Nanosilica from Paddy Husk Ash and Their Surface Functionalization. Sci. Univ. Kelaniya 8 33-48.

[26] Atul Jyoti a, Rakesh Kr Singh, Nishant Kumar, (2021) Materials Science and Engineering B 263 114871. https://doi.org/10.1016/j.mseb.2020.114871

[27] S. Sankar, Narinder Kaur, Sejoon Lee, Deuk Young Kim (2018), Rapid sonochemical synthesis of spherical silica nanoparticles derived from brown rice husk. Ceramics International, 44, 8720-8724. https://doi.org/10.1016/j.ceramint.2018.02.090

[28] Sung Bum Park, Won Hoon Jung, Ki Young Kim and Byumseok Koh, Molecules, 2020, 25, 3594; doi:10.3390/molecules25163594.

https://doi.org/10.3390/molecules25163594

[29] Tao Xie, Xufeng Zhong, Zhengjie Liu \& Chenggen Xie, (2020) Silica-anchored cadmium sulfide nanocrystals for the opticaldetection of copper (II). Microchimica Acta 187: 323. https://doi.org/10.1007/s00604-020-04295-

[30] Haitao Liu, Zhaohui Huang, Juntong Huang, Song Xu, Minghao Fang, Yan-gai Liu, Xiaowen Wu \& Shaowei Zhang, Scientific Reports, 6:22459; https: //doi.org/10.1038/srep22459.

[31] Kaleli Mbinda Jonathan, Kamweru Paul Kuria1, Gichumbi Joel Mwangi and Ndiritu Francis Gichuk ol.11(2), pp. 24-

30 https://doi.org/10.5897/JCEMS2020.0348

\section{Figures}
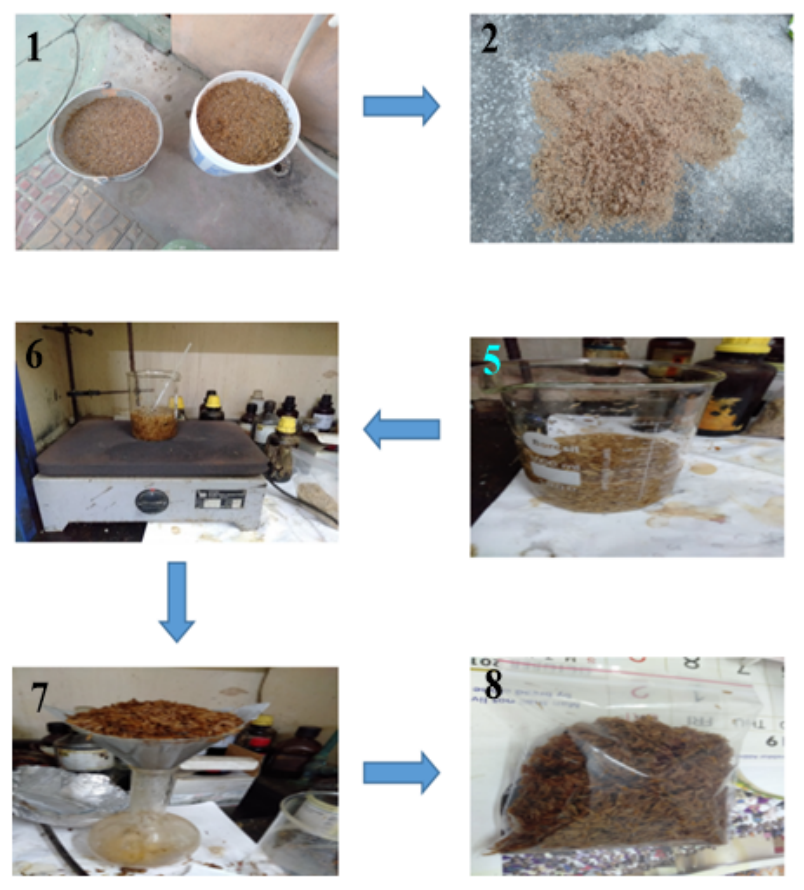
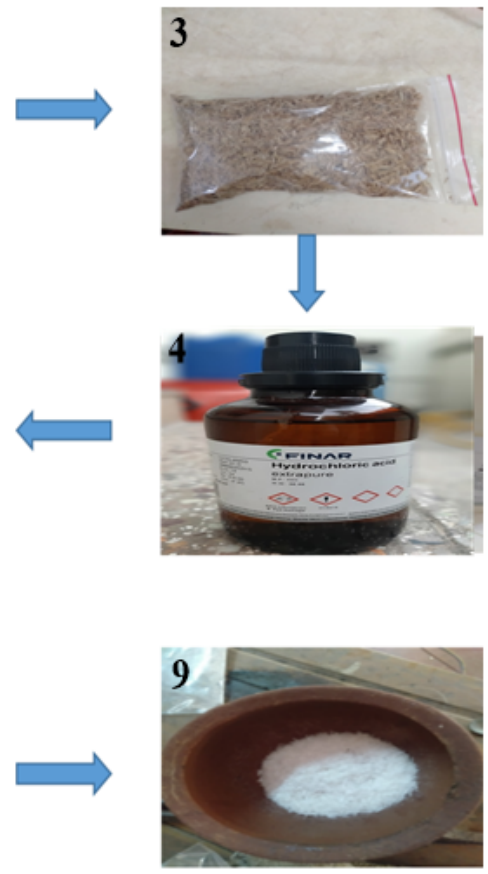

\section{Figure 1}

Steps Involved in the Preparation of $1 \mathrm{M} \mathrm{HCl}$ Treated Silica. 1) Soaked in salt water 2) Dried 3) Packed rice hull 4) Conc. $\mathrm{HCl} 5) 1 \mathrm{M} \mathrm{HCl} \mathrm{treated} \mathrm{rice} \mathrm{hull.} \mathrm{6)}$ Leaching operation 7) Water wash 8) Sealed in airtight bag 9) $\mathrm{SiO} 2\left(600{ }^{\circ} \mathrm{C}\right)$. 

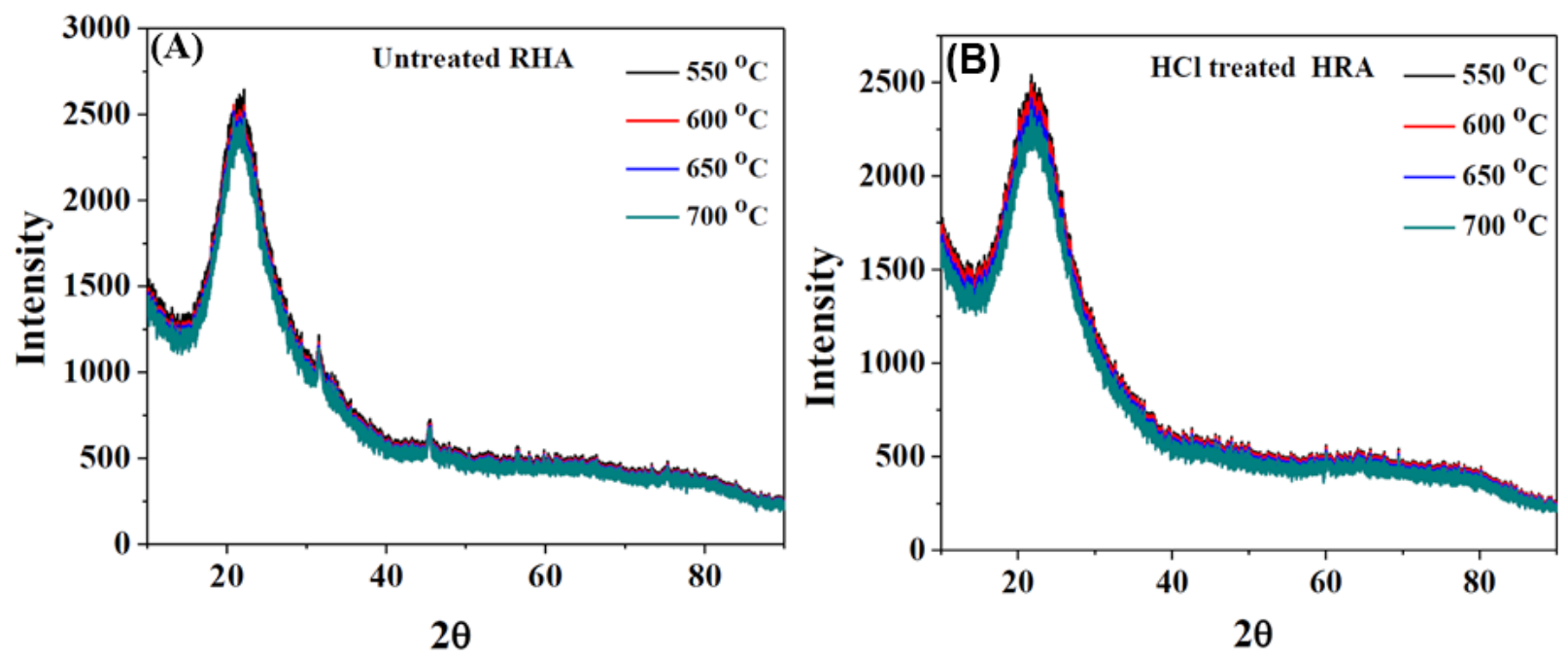

Figure 2

XRD spectra of A) Untreated RHA at various temperatures, B) $1 \mathrm{M} \mathrm{HCl}$ treated $\mathrm{RHA}$ at various temperatures.

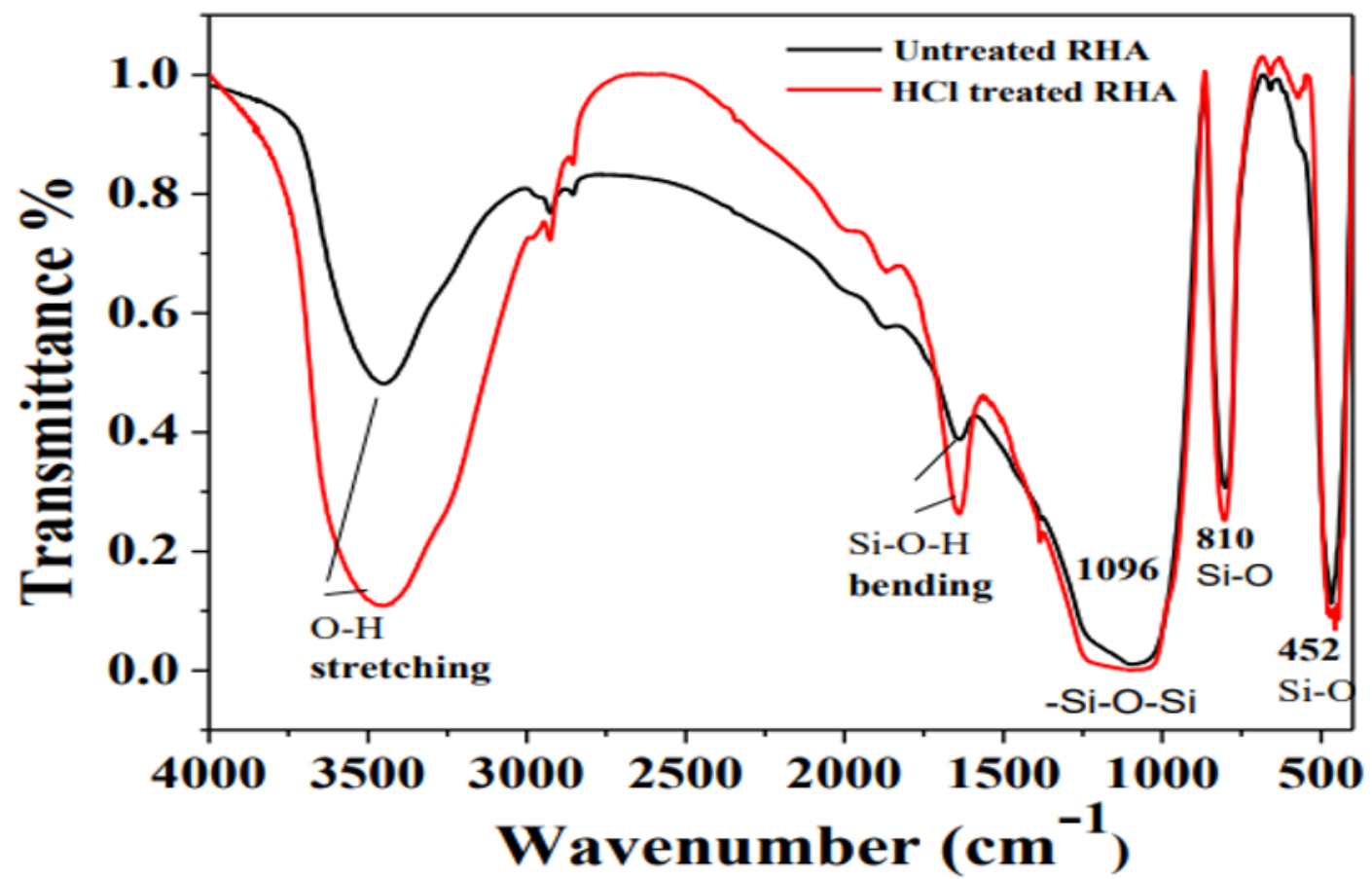

Figure 3

FT-IR spectra of A) Untreated RHA B) $1 \mathrm{M} \mathrm{HCl}$ treated RHA operated at room temperature.<smiles>C[Si]1(C)O[Si](C)(C)O[Si]2(C)O[Si]3(C)O[Si](C)(C)O[Si]4(C)O[Si](C)(C)O[Si](C)(O1)O[Si](O[Si](C)(C)O3)(O4)O2</smiles> 
Figure 4

Structure of Silica [6]
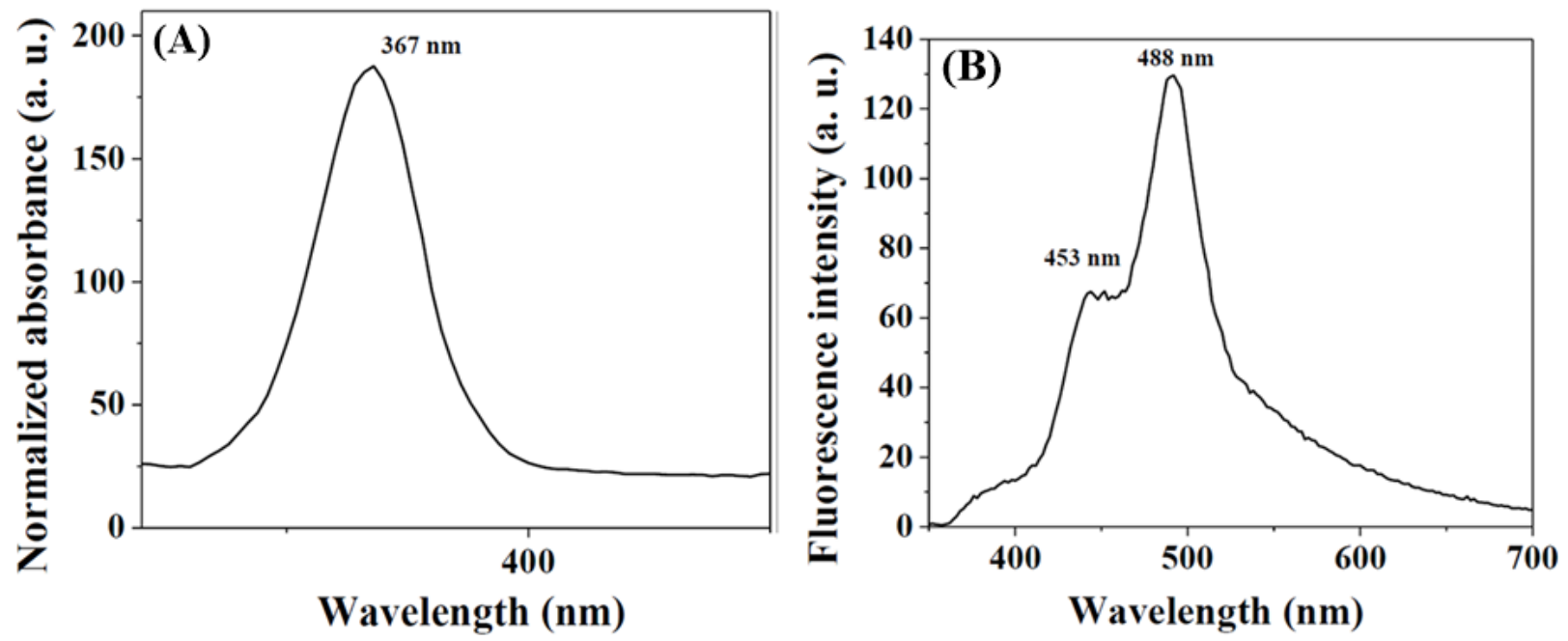

Figure 5

Fluorescence Spectrophotometer (A) Absorption spectrum of natural silica (1 mM solubilized in chloroform), (B) Emission spectrum of natural silica (1 mM solubilized in chloroform).
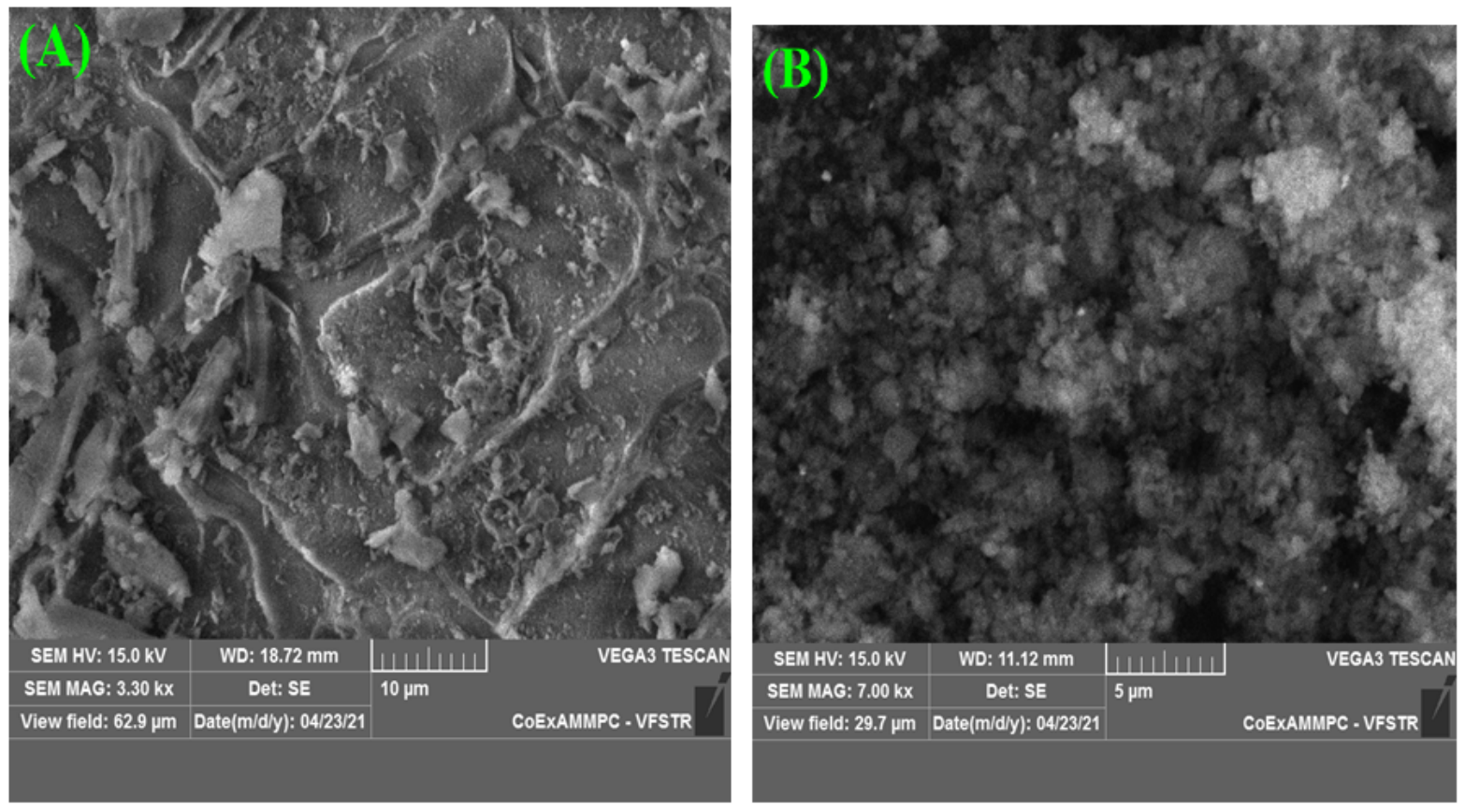

Figure 6

SEM A) Untreated SiO2 B) HCl treated SiO2 after Ball Mill. 


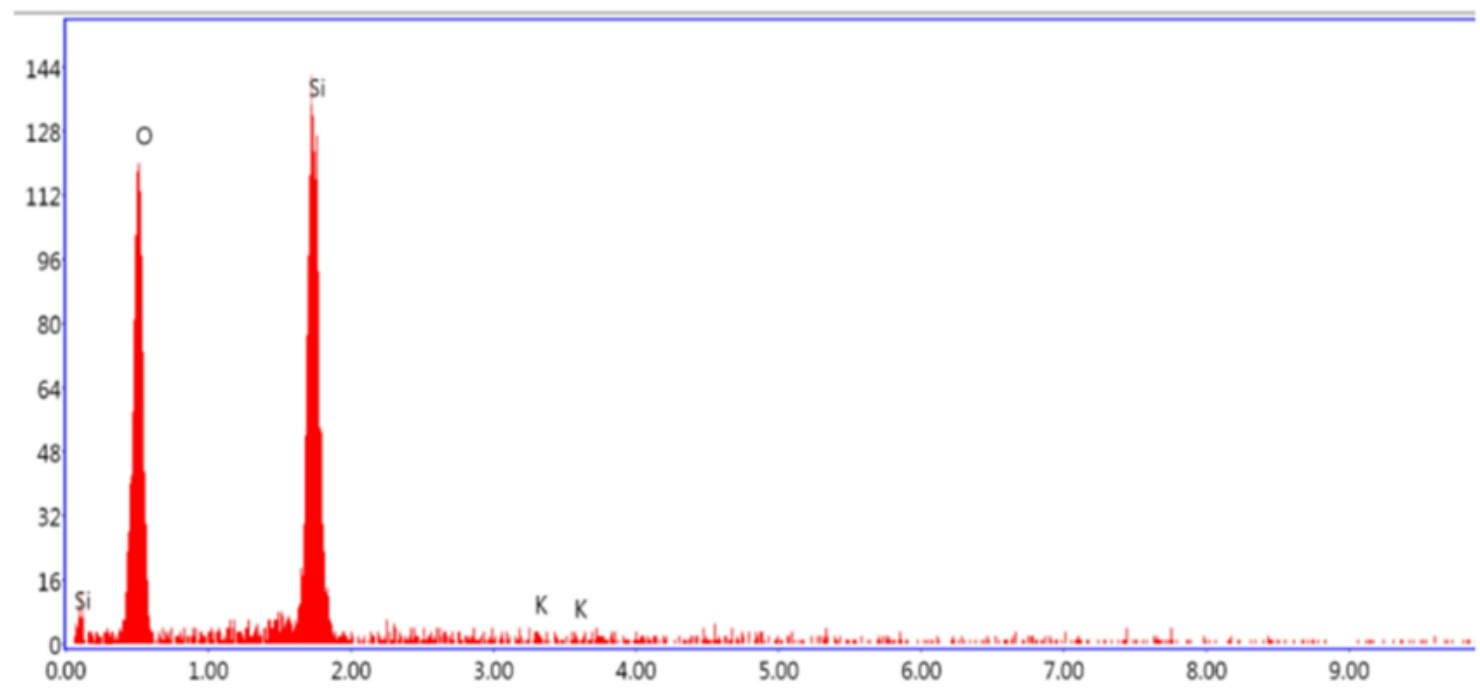

Figure 7

EDS of $(\mathrm{HCl})$ Acid treated Silica. 